\title{
Effects of anabolic implants and ractopamine-HCl on muscle fiber morphomet- rics, collagen solubility, and tenderness of beef longissimus lumborum steaks ${ }^{1,2}$
}

\author{
S. M. Ebarb,* K. J. Phelps,* J. S. Drouillard,* K. R. Maddock-Carlin†, M. A. Vaughn,* \\ D. D. Burnett,* J. A. Noel,* C. L. Van Bibber- Krueger,* C. B. Paulk, \$ D. M. Grieger,* and J. M. Gonzalez*3 \\ * Department of Animal Sciences and Industry, Kansas State University, \\ Manhattan 66506; †Department of Animal Sciences, North Dakota State University, \\ Fargo 58102; \$Department of Animal Science, Texas A\&M University, College Station 77840
}

\begin{abstract}
The objective of this study was to examine the effects of growth-promoting technologies (GP) and postmortem aging on longissimus lumborum muscle fiber cross-sectional area (CSA), collagen solubility, and their relationship to meat tenderness. Two groups of black-hided crossbred feedlot heifers (group $1: n=33$, initial BW $430 \pm 7 \mathrm{~kg}$; group $2: n=32$, initial BW $466 \pm 7 \mathrm{~kg}$ ) were blocked by BW and assigned to 1 of 3 treatments consisting of: no implant and no ractopamine hydrochloride (CON; $n=21)$; implant, no ractopamine hydrochloride (IMP; $n=22$ ); implant and ractopamine hydrochloride (COMBO; $n=22)$. Heifers that received an implant were administered an implant containing $200 \mathrm{mg}$ trenbolone acetate and $20 \mathrm{mg}$ estradiol on $\mathrm{d} 0$ of the study, and heifers in the COMBO group received $400 \mathrm{mg} \cdot \mathrm{head}^{-1} \cdot \mathrm{d}^{-1}$ of ractopamine hydrochloride for 28 (Group 1) or $29 \mathrm{~d}$ (Group 2) at the end of 90- (Group 1) or 106-d (Group 2) feeding period. Following harvest, strip loins were collected and further fabricated into 5 roasts for postmortem aging (DOA) periods of 2, 7, 14, 21, or $35 \mathrm{~d}$. After aging, Warner-Bratzler shear force (WBSF), muscle fiber CSA, and collagen solubility were measured. There was no treatment $\times$ DOA interaction for WBSF $(P=$
\end{abstract}

$0.86)$, but treatment and DOA impacted WBSF $(P<$ $0.01)$. Over the entire aging study, COMBO steaks had greater $(P<0.01)$ shear force values when compared to CON steaks. The IMP steaks tended to have decreased $(P=0.07)$ shear force when compared to the COMBO steaks, but did not differ $(P=0.11)$ from CON steaks. The IMP and COMBO treatments had increased type IIA fiber CSA when compared to CON $(P<0.01)$. When compared to each other, the IMP and COMBO type IIA fiber CSA did not differ $(P=0.76)$. Type I and IIX fiber CSA tended to be greater than CON for IMP and COMBO treatments $(P<0.10)$. There was no treatment $\times$ DOA interaction for all collagen measures $(P>0.33)$. Collagen amounts were not impacted by GP treatment $(P>0.72)$, but DOA increased the concentration of soluble collagen $(P=0.04)$. Fiber CSA of all fiber types were positively correlated $(P<0.05 ; r=$ 0.21 to 0.28 ) with WBSF only on $\mathrm{d} 2$ of aging, while soluble collagen amount tended to negatively correlate with WBSF on $\mathrm{d} 7$ and 14 of aging $(P<0.10 ; r=-0.24$ and -0.23 , respectively). Administration of GP during heifer finishing resulted in greater steak WBSF over $35 \mathrm{~d}$ of aging, which was not due to collagen characteristics and only minimally affected by fiber CSA.

Key words: collagen, extended aging, implants, muscle fiber type, ractopamine hydrochloride

\section{INTRODUCTION}

\footnotetext{
${ }^{1}$ This project was funded in part by The Beef Checkoff.

${ }^{2}$ Contribution no. 17-007-J of the Kansas Agricultural Experiment Station, Manhattan 66506

${ }^{3}$ Corresponding author: johngonz@k-state.edu

Received December 1, 2016.

Accepted January 6, 2017.
}

Growth-promoting technologies (GP) are important for improving efficiency and increasing yields of feedlot cattle. Anabolic implants and $\beta$-adrenergic agonists (BAA) are the 2 most common GP utilized by producers. Implants containing trenbolone acetate (TBA) and estradiol $\left(\mathbf{E}_{\mathbf{2}}\right)$ enhance feedlot performance 
and carcass characteristics and may yield the producer a profit of \$163 per head (Duckett and Pratt, 2014). Since zilpaterol hydrochloride (ZH) was voluntarily removed from the marketplace, ractopamine hydrochloride $(\mathbf{R H})$ remains the sole BAA available for producers to utilize. While not as potent as ZH, Lean et al. (2014) estimated RH increases ADG by $0.19 \mathrm{~kg} / \mathrm{d}, \mathrm{LM}$ area by $1.84 \mathrm{~cm}^{2}$, and Warner-Bratzler shear force (WBSF) by $0.2 \mathrm{~kg}$.

Factors influencing meat tenderness can impact overall consumer acceptability of beef products (Lusk et al., 2001). Previous literature demonstrated GP negatively impact tenderness through increased calpastatin activity (Gerken et al., 1995; Strydom et al., 2009), but little attention has been focused on the muscle structure. Ebarb et al. (2016) found the reduction in tenderness caused by GP was due to increased muscle fiber cross-sectional area (CSA), but collagen solubility was not affected by GP treatment. Roy et al. (2015) reported hydroxylysyl pyridinoline (HP) crosslinks increased within the gluteus medius and semitendinosus when steers were administered an implant, but RH supplementation did not impact HP content. These 2 studies indicate different combinations of GP can negatively affect meat tenderness through increases in muscle fiber CSA or HP cross-link formation, but these alterations have not be observed simultaneously in the LM during postmortem aging. The objective of this study was to examine the effect of GP and aging on skeletal muscle fiber and collagen characteristics of the longissimus lumborum and determine their relationship to beef tenderness.

\section{MATERIALS AND METHODS}

All experimental procedures were approved by the Kansas State University Institutional Animal Care and Use Committee.

\section{Heifer Management}

Two groups of black-hided, crossbred feedlot heifers (group 1: $n=33$, initial BW $430 \mathrm{~kg} \pm 7$; group 2: $n=$ 33 , initial BW $466 \mathrm{~kg} \pm 7$ ) approximately 16 to $18 \mathrm{mo}$ of age were housed in individual pens located in an enclosed barn at the Kansas State University Beef Cattle Research Center. Each pen was $4.64 \mathrm{~m}^{2}$ and contained metal pipe sidewalls, slatted floors for waste removal, an individual waterer, and a $75 \mathrm{~cm} \times 51 \mathrm{~cm}$ feed bunk. After a 10-d acclimation period for each replication, heifers were weighed, stratified from heaviest to lightest BW, and within each stratum of 3 heifers, randomly assigned to 1 of 3 treatments: no implant and no $\mathrm{RH}$ (CON; $n=22)$; implant, no RH (IMP; $n=22)$; or implant and RH (COMBO; $n=22)$. Heifers in the IMP and COMBO treatments were administered an implant containing $200 \mathrm{mg}$ TBA and $20 \mathrm{mg}$ E2 (Component TE-200, Elanco Animal Health, Greenfield, IN). Heifers in the COMBO treatment received $400 \mathrm{mg}^{\cdot} \mathrm{d}^{-1} \cdot$ heifer $^{-1}$ of RH (Optaflexx; Elanco Animal Health) for $28 \mathrm{~d}$ (group 1) or $29 \mathrm{~d}$ (group 2) before harvest. Ractopamine hydrochloride was mixed into the mineral and vitamin supplement which was then incorporated into the total mixed ration. Heifers were fed experimental diets (Table 1) once daily to allow ad libitum access to feed for $90 \mathrm{~d}$ (group 1) or $106 \mathrm{~d}$ (group 2). Bunks were managed to leave a minimum of $227 \mathrm{~g}$ of unconsumed feed per head daily. One heifer from the CON treatment in group 2 was removed from study due to injury.

\section{Harvest and Sampling Procedures}

When the experimental finishing period for each group was completed, heifers were weighed and shipped $275 \mathrm{~km}$ to a commercial abattoir (Creekstone Farms, Arkansas City, KS) for harvest. Individual HCW for each heifer were recorded on the day of harvest, and carcasses were allowed to chill for $48 \mathrm{~h}$ before the collection of the remainder of carcass measurements and collection of strip loins. Marbling scores were assigned by a USDA grader, while LM area and 12th rib s. c. fat were instrumentally collected (VBG 2000; e + v Technology GmbH \& Co. KG, Oranienburg, Germany). Dressing percentage for each carcass was calculated as $(\mathrm{HCW} /$ live weight $) \times 100$. Strip loins (Institutional Meat Purchasing Specifications 180; North American Meat Processors, 2010) were collected and transported to the Kansas State University Meat Laboratory for further fabrication. Upon arrival, loin weight was recorded and a $1.27-\mathrm{cm}$ thick steak was removed from the anterior portion of the muscle, beginning at the 13th rib of each loin, and was used for immunohistochemical analysis. Ultimate $\mathrm{pH}$ was measured using a meat $\mathrm{pH}$ meter (model HI 99163; Hanna Instruments, Smithfield, $\mathrm{RI})$ at the geometric center of the loin. The loin was fabricated into five $5.08-\mathrm{cm}$ thick roasts and roasts were randomly assigned to a postmortem aging period of 2 , $7,14,21$, or $35 \mathrm{~d}$ of aging (DOA). Roasts were vacuum packaged and aged to their assigned DOA at $5 \pm$ $1{ }^{\circ} \mathrm{C}$. Additionally, the remaining portion of the loin was weighed for purge loss calculations before being vacuum packaged and stored until d-21 postmortem. After aging, roasts were cut into one $2.54-\mathrm{cm}$ steak for WBSF and one $2.54-\mathrm{cm}$ steak for collagen solubility analysis. Steaks were frozen and stored in a blast cooler at $-40^{\circ} \mathrm{C}$ until further analysis was completed. At $\mathrm{d} 21$ of aging, the remaining loin was weighed again for purge loss calculations [(initial loin weight-aged loin weight)/initial loin weight] $\times 100$ and $\mathrm{pH}$ was once again recorded. 
Table 1. Diet composition (DM basis) for crossbred heifers subjected to 3 exogenous growth-promoting programs

\begin{tabular}{|c|c|c|c|c|c|c|}
\hline \multirow[b]{3}{*}{ Ingredient, \% } & \multicolumn{3}{|c|}{ Group $1(n=33)$} & \multicolumn{3}{|c|}{ Group $2(n=32)$} \\
\hline & \multicolumn{3}{|c|}{ Treatments $^{1}$} & \multicolumn{3}{|c|}{ Treatments $^{1}$} \\
\hline & $\mathrm{CON}$ & IMP & COMBO & $\mathrm{CON}$ & IMP & COMBO \\
\hline Steam-flaked corn & 57.90 & 57.90 & 57.90 & 57.79 & 57.79 & 57.79 \\
\hline Wet corn gluten feed & 30.00 & 30.00 & 30.00 & 30.00 & 30.00 & 30.00 \\
\hline Ground alfalfa hay & 8.00 & 8.00 & 8.00 & 8.00 & 8.00 & 8.00 \\
\hline \multicolumn{7}{|l|}{ Mineral/vitamin supplement } \\
\hline Ground limestone & 1.47 & 1.47 & 1.47 & 1.46 & 1.46 & 1.46 \\
\hline Salt & 0.30 & 0.30 & 0.30 & 0.30 & 0.30 & 0.30 \\
\hline Potassium chloride & 0.05 & 0.05 & 0.05 & 0.05 & 0.05 & 0.05 \\
\hline Vitamin A & 0.007 & 0.007 & 0.007 & 0.007 & 0.007 & 0.007 \\
\hline Vitamin E & 0.05 & 0.05 & 0.05 & 0.05 & 0.05 & 0.05 \\
\hline Monensin and tylosin premix ${ }^{2}$ & 2.16 & 2.16 & 2.16 & 2.27 & 2.27 & 2.27 \\
\hline \multicolumn{7}{|l|}{ Calculated nutrient composition } \\
\hline $\mathrm{NEm}, \mathrm{Mcal} / \mathrm{kg}$ & 0.96 & 0.96 & 0.96 & 0.96 & 0.96 & 0.96 \\
\hline $\mathrm{NEg}, \mathrm{Mcal} / \mathrm{kg}$ & 0.66 & 0.66 & 0.66 & 0.66 & 0.66 & 0.66 \\
\hline $\mathrm{ADF}, \%$ & 8.36 & 8.36 & 8.36 & 8.36 & 8.36 & 8.36 \\
\hline NDF, \% & 19.44 & 19.44 & 19.44 & 19.41 & 19.44 & 19. 44 \\
\hline $\mathrm{CP}, \%$ & 14.12 & 14.12 & 14.12 & 14.12 & 14.12 & 14.12 \\
\hline Ether extract, \% & 3.67 & 3.67 & 3.67 & 3.67 & 3.67 & 3. 67 \\
\hline $\mathrm{Ca}, \%$ & 0.70 & 0.70 & 0.70 & 0.70 & 0.70 & 0.70 \\
\hline $\mathrm{P}, \%$ & 0.48 & 0.48 & 0.48 & 0.48 & 0.48 & 0.48 \\
\hline $\mathrm{K}, \%$ & 0.70 & 0.70 & 0.70 & 0.70 & 0.70 & 0.70 \\
\hline Vitamin A (added), IU/kg & 2205 & 2205 & 2205 & 2205 & 2205 & 2205 \\
\hline Vitamin E (added), IU/kg & 22 & 22 & 22 & 22 & 22 & 22 \\
\hline
\end{tabular}

\section{Immunohistochemistry}

The methods of Phelps et al. (2014) and Ebarb et al. (2016) were followed for immunohistochemical analysis. Briefly, a $1 \mathrm{~cm} \times 1 \mathrm{~cm} \times 1.27 \mathrm{~cm}$ sample was collected from the geometric center of the medial, medial/lateral, and lateral areas of the muscle. Samples were embedded and frozen in optimum cutting temperature tissue freezing medium (Fisher Scientific, Pittsburgh, PA) using liquid nitrogen cooled, 2-methyl-butane (Fisher Scientific). Five-micrometer cryosections were incubated in a primary antibody cocktail consisting of anti-dystrophin (Thermo Scientific, Waltman, MA), anti-slow myosin heavy chain type I (BA-D5, Developmental Studies Hybridoma Bank, Iowa City, IA), and anti-myosin heavy chain all but type IIX (BF-35, Developmental Studies Hybridoma Bank). Following washing and incubation with the appropriate secondary antibodies, photomicrographs were captured using a Nikon Eclipse TI-U inverted microscope equipped with a DS-QiMC digital camera at a $100 \times$ magnification (Nikon Instruments Inc., Melville, NY). Cross-sectional area of a minimum of 200 muscle fibers from each location of each animal were analyzed by myosin heavy chain isoform. Fibers staining positive for BA-D5 were classified as type I fi- bers. Fibers staining positive for BF-35, but negative for BA-D5 were considered type IIA fibers. Fibers staining negative for both BA-D5 and BF-35 were considered type IIX fibers (Moreno-Sánchez et al., 2008; Schiaffino et al., 1989). Muscle CSA by fiber type were averaged over the 3 locations to yield a steak average.

\section{Cooking and Warner-Bratzler Shear Force}

Cooking procedures for WBSF followed the American Meat Science Association's (AMSA) Meat Cookery and Sensory Guidelines (AMSA, 1995). Prior to cooking, frozen steaks were removed from their vacuum packages, placed on a metal tray with an absorbent pad (Dri-Loc 50, Cyrovac Sealed Air Corporation, Duncun, SC), covered in plastic food wrap (Sysco Corporation, Houston, TX), and allowed to thaw for $24 \mathrm{~h}$ at $7 \pm 1^{\circ} \mathrm{C}$. After thawing, steaks were weighed and a thermocouple wire (30-gauge copper and constantan; Omega Engineering, Stamford, CT) was inserted into the geometric center of each steak. Internal temperature was monitored throughout cooking using a Doric Minitrend 205 monitor (VAS Engineering, San Francisco, CA). Steaks were cooked on a Cuisinart 
Table 2. Carcass characteristics and boneless strip loin (IMPS 180) characteristics of crossbred heifers subjected to 3 exogenous growth-promoting programs

\begin{tabular}{|c|c|c|c|c|c|}
\hline \multirow[b]{2}{*}{ Item } & \multicolumn{3}{|c|}{ Treatment $^{1}$} & \multirow[b]{2}{*}{ SEM } & \multirow[b]{2}{*}{$P$-value } \\
\hline & $\mathrm{CON}$ & IMP & COMBO & & \\
\hline$\overline{\mathrm{HCW}}, \mathrm{kg}$ & $327.1^{\mathrm{a}, \mathrm{x}}$ & $340.7^{y}$ & $341.9^{\mathrm{b}, \mathrm{y}}$ & 5.2 & 0.09 \\
\hline Dressing percentage, $\%$ & 63.6 & 63.8 & 64.3 & 0.4 & 0.41 \\
\hline USDA yield grade & 2.8 & 2.3 & 2.4 & 0.2 & 0.12 \\
\hline $\mathrm{LM}$ area, $\mathrm{cm}^{2}$ & $84.2^{\mathrm{a}}$ & $91.2^{\mathrm{b}}$ & $92.6^{\mathrm{b}}$ & 0.3 & 0.01 \\
\hline 12th-rib s.c. fat, cm & 1.3 & 1.1 & 1.2 & 0.1 & 0.45 \\
\hline USDA marbling score ${ }^{2}$ & 519 & 503 & 519 & 20 & 0.80 \\
\hline Initial loin weight, kg & $5.71^{\mathrm{a}}$ & $6.16^{\mathrm{b}}$ & $6.14^{\mathrm{b}}$ & 0.14 & 0.05 \\
\hline Purge loss $3, \%$ & 3.97 & 4.37 & 3.40 & 0.59 & 0.49 \\
\hline
\end{tabular}

a,b Means within a row with a different superscript differ $(P<0.05)$. ${ }^{\mathrm{x}, \mathrm{y}}$ Means within a row with a different superscript tend to differ $(P<0.10)$.

${ }^{1}$ Crossbred heifers (group 1, $n=33$; group 2, $n=32$ ) were subjected to 1 of 3 treatments: no implant and no ractopamine hydrochloride (CON; Elanco Animal Health, Greenfield, IN); Component TE-200 implant (Elanco Animal Health) on d 0, no ractopamine hydrochloride (IMP); and Component TE-200 implant on $\mathrm{d} 0$ and ractopamine hydrochloride at $400 \mathrm{mg} \cdot \mathrm{d}^{-1} \cdot$ heifer $^{-1}$ for the last $28 \mathrm{~d}$ in group 1 and last $29 \mathrm{~d}$ in group 2 (COMBO).

${ }^{2}$ USDA marbling scores: $400-499=$ Slight; $500-599=$ Small.

${ }^{3}$ Purge loss calculated by ([initial loin weight-final loin weight]/initial loin weight) $\times 100$. Initial and final ( 21$)$ loin weight collected on posterior portion of the strip loin that remained following removal of steaks from the anterior end for Warner-Bratzler shear force analysis.

Griddler (Cuisinart, Stamford, CT) set at $232^{\circ} \mathrm{C}$ until the internal temperature at the geometric center reached $65^{\circ} \mathrm{C}$. Steaks were removed from grills, allowed to rest until reaching a peak temperature of $71^{\circ} \mathrm{C}$. Steaks were then allowed to cool for approximately $10 \mathrm{~min}$ and a final weight was obtained for the calculation of percent cook loss [(uncooked weight- cooked weight)/uncooked weight $] \times 100$. After a 24 -h chill period at $7 \pm$ $1{ }^{\circ} \mathrm{C}$, six $1.27-\mathrm{cm}$ cores were removed from across the steak parallel to the muscle fiber orientation. Each core was sheared once perpendicular to the muscle fiber orientation using a Warner-Bratzler shear head attached to an INSTRON Universal Testing Machine (Model 5569; Instron, Canton, MA) with a $100 \mathrm{~kg}$ compression load cell and a crosshead speed of $250 \mathrm{~mm} / \mathrm{min}$.

\section{Collagen Solubility}

Each steak for collagen analysis was diced, frozen in liquid nitrogen, pulverized using a Waring blender (Waring Products Division, Hartford, CT), and stored at $-20^{\circ} \mathrm{C}$ until analysis. Hydroxyproline content was determined using the protocol adapted from Hill (1966) and official Association of Official Analytical Chemists (AOAC) method 990.26 (AOAC, 2005). One gram of pulverized, freeze-dried tissue was mixed with $12 \mathrm{~mL}$ of $1 / 4$ strength Ringer's solution and incubated in a $77^{\circ} \mathrm{C}$ water bath for $80 \mathrm{~min}$. Following incubation, samples were centrifuged at $2250 \times g$ for $12 \mathrm{~min}$ at $20^{\circ} \mathrm{C}$ to separate the supernatant consisting of the soluble collagen from the insoluble pellet. The supernatant was decanted into a separate tube and 3 $\mathrm{mL}$ of $1 / 4$ strength Ringer's solution was added to the insoluble pellet and centrifuged again. Sulfuric acid was added $(3 \mathrm{~mL}$ concentrated sulfuric acid to soluble portion; $30 \mathrm{~mL} 3.5 \mathrm{M}$ sulfuric acid to the insoluble portion) and the fractions were incubated at $105^{\circ} \mathrm{C}$ for $16 \mathrm{~h}$. Samples were removed and cooled for a minimum of $30 \mathrm{~min}$. Once cooled, samples were diluted with deionized water to $250 \mathrm{~mL}$ for the soluble fraction and $500 \mathrm{~mL}$ for the insoluble fraction, mixed well, and filtered through Whatman 541 filter paper (Fisher Scientific; Waltham, MA) into $15-\mathrm{mL}$ glass tube. Hydroxyproline determination was performed following the procedures outlined by Bergman and Loxley (1963) using a spectrophotometer (BioTek Eon; Biotek Instruments Inc., Winooski, VT) reading absorbance at $558 \mathrm{~nm}$. The spectrophotometer was calibrated using a distilled water blank sample, and readings were quantified by standard curves prepared on each day of analysis. Total and fractional collagen content was determined by multiplying the hydroxyproline content of the soluble fraction by 7.25 and the insoluble fraction by 7.52 (Cross et al., 1973).

\section{Hydroxylysyl Pyridinoline Analysis}

A sub-set of samples, randomly selected from each treatment group (CON, $n=7$; IMP, $n=7$; COMBO, $n=8$ ), for quantification of the collagen crosslink HP were extracted according to procedures described by Smith and Judge (1991) with modifications. Muscle samples were pulverized in liquid $\mathrm{N}$ and $0.5 \mathrm{~g}$ of each sample was dried in a $60^{\circ} \mathrm{C}$ drying oven. Once dry, $100 \mathrm{mg}$ of each sample was hydrolyzed in $2 \mathrm{~mL}$ of $6 M \mathrm{HCl}$ at $100^{\circ} \mathrm{C}$ for $16 \mathrm{~h}$. Hydrolysates were allowed to cool in darkness for $30 \mathrm{~min}$ and then were filtered through Whatman \#1 filter paper (Whatman; GE Healthcare Bio- Sciences, Pittsburgh, PA). After filtration, the $\mathrm{pH}$ of samples was adjusted to $7.0 \pm 0.1$, 
Table 3. Longissimus lumborum $\mathrm{pH}$, and d 2, 7, 14, 21, or 35 cook loss of steaks from crossbred heifers subjected to 3 growth-promoting programs

\begin{tabular}{|c|c|c|c|c|c|c|c|}
\hline \multirow[b]{2}{*}{ Objective measures } & \multicolumn{3}{|c|}{ Treatment $^{1}$} & \multirow[b]{2}{*}{ SEM } & \multicolumn{3}{|c|}{$P$-value } \\
\hline & $\mathrm{CON}$ & IMP & COMBO & & $\overline{\mathrm{Trt}^{2}}$ & $\mathrm{DOA}^{3}$ & Trt $\times$ DOA \\
\hline Muscle $\mathrm{pH}^{4}$ & & & & 0.01 & 0.98 & $<0.01$ & 0.56 \\
\hline Day $2^{\mathrm{a}}$ & 5.49 & 5.49 & 5.50 & & & & \\
\hline Day $21^{\mathrm{b}}$ & 5.60 & 5.59 & 5.59 & & & & \\
\hline Cook loss $5, \%$ & & & & 0.62 & 0.23 & 0.61 & 0.34 \\
\hline Day 2 & 20.80 & 22.78 & 23.58 & & & & \\
\hline Day 7 & 22.36 & 22.60 & 22.24 & & & & \\
\hline Day 14 & 21.90 & 22.23 & 22.32 & & & & \\
\hline Day 21 & 22.02 & 22.73 & 22.49 & & & & \\
\hline Day 35 & 22.60 & 22.70 & 23.33 & & & & \\
\hline \multicolumn{8}{|c|}{ a,b Days within $\mathrm{pH}$ with a different superscript differ $(P<0.05)$} \\
\hline \multicolumn{8}{|c|}{$\begin{array}{l}{ }^{1} \text { Crossbred heifers (group } 1, n=33 \text {; group } 2, n=32 \text { ) were subjected to } 1 \text { of } 3 \text { treatments: no implant and no ractopamine hydrochloride (CON; Elanco } \\
\text { Animal Health, Greenfield, IN); Component TE- } 200 \mathrm{implant} \text { (Elanco Animal Health) on d } 0 \text {, no ractopamine hydrochloride (IMP); and Component TE-200 } \\
\text { implant on d } 0 \text { and ractopamine hydrochloride at } 400 \mathrm{mg} \cdot \mathrm{d}^{-1} \cdot \text { heifer }^{-1} \text { for the last } 28 \mathrm{~d} \text { in group } 1 \text { and last } 29 \mathrm{~d} \text { in group } 2 \text { (COMBO). }\end{array}$} \\
\hline \multicolumn{8}{|c|}{${ }^{2} \mathrm{Trt}=$ Treatment. } \\
\hline \multicolumn{8}{|c|}{${ }^{3} \mathrm{DOA}=$ Day of aging. } \\
\hline${ }^{4} \mathrm{pH}$ was measure & $\mathrm{pH}$ met & $1 \mathrm{HI} 991$ & nna Instrum & nithfiel & $\mathrm{n}$ the $\mathrm{g}$ & center o & rip loin on $\mathrm{Da}$ \\
\hline
\end{tabular}

and the final sample volume was brought to $10 \mathrm{~mL}$ with ultrapure water. The HP concentration of each sample was measured using a commercial ELISA kit (Microvue PYD; Quidel, San Diego, CA). The kit instructions were strictly followed. The amount of HP is expressed as $\mathrm{ng} \mathrm{HP} / \mathrm{g}$ of wet tissue.

\section{Statistical Analyses}

There were no treatment $\times$ group interactions for all dependent variables; therefore, data were pooled. Carcass characteristics and muscle fiber data were analyzed as a randomized complete block design utilizing animal as the experimental unit and initial BW as the blocking factor. Growth-promoting treatment served as the fixed effect and animal within initial BW block served as the random effect. Collagen solubility, HP content, WBSF, and pH were analyzed as a randomized complete block design with repeated measures with day as the repeated measure, animal/ loin as the subject, and compound symmetry as the covariance structure. Peak temperature was utilized as a covariate when analyzing WBSF. All data were analyzed utilizing the PROC MIXED procedure of SAS (SAS Inst. Inc., Cary, NC) and pairwise comparisons between the least squares means of the factor levels comparisons, were computed using the PDIFF option of the LSMEANS statement. Correlations between WBSF and muscle characteristics were computed using the PROC CORR procedure of SAS. Differences were considered significant at $P \leq 0.05$ and tendencies at $P>0.05$ and $P \leq 0.10$.

\section{RESULTS}

\section{Carcass Characteristics and Loin Measures}

Hot carcass weight tended to differ $(P=0.09)$ due to GP treatment; however, dressing percentage did not differ $(P=0.41$; Table 2$)$. Carcasses from the IMP treatment tended to be heavier $(P=0.07)$ than $\mathrm{CON}$ carcasses. Carcasses from the COMBO treatment were heavier $(P=0.05)$ than CON carcasses, but did not differ $(P=0.86)$ from IMP carcasses. Growth promotant treatment affected LM area $(P=0.01)$, with COMBO and IMP carcasses having larger LM area than CON carcasses $(P<0.01)$. Carcasses from COMBO and IMP treatments had similar $(P=0.53)$ LM area when compared to one another. Adipose measurements, including 12th-rib s. c. fat and marbling, were unaffected by GP treatment $(P>0.45)$. In agreement with LM area data, when IMPS 180 loins were fabricated from carcasses, weight was affected $(P=0.05)$ by GP treatment. Loins from COMBO and IMP carcasses were heavier compared to CON loins $(P<0.03)$, but were not different $(P$ $=0.94$ ) from each other. Purge loss after $21 \mathrm{~d}$ of aging was not affected $(P=0.49)$ by GP treatment.

\section{Warner-Bratzler Shear Force, Cook Loss, and pH}

There were no treatment $\times$ DOA interactions for $\mathrm{pH}$, cook loss (Table 3), or WBSF $(P>0.34$; Fig. 1$)$. Growth-promoting treatment did not affect $(P=0.98)$ $\mathrm{pH}$, but at 21 DOA, $\mathrm{pH}$ increased $(P=0.01)$ when compared to the initial $\mathrm{pH}$ measurement. Percent cook 


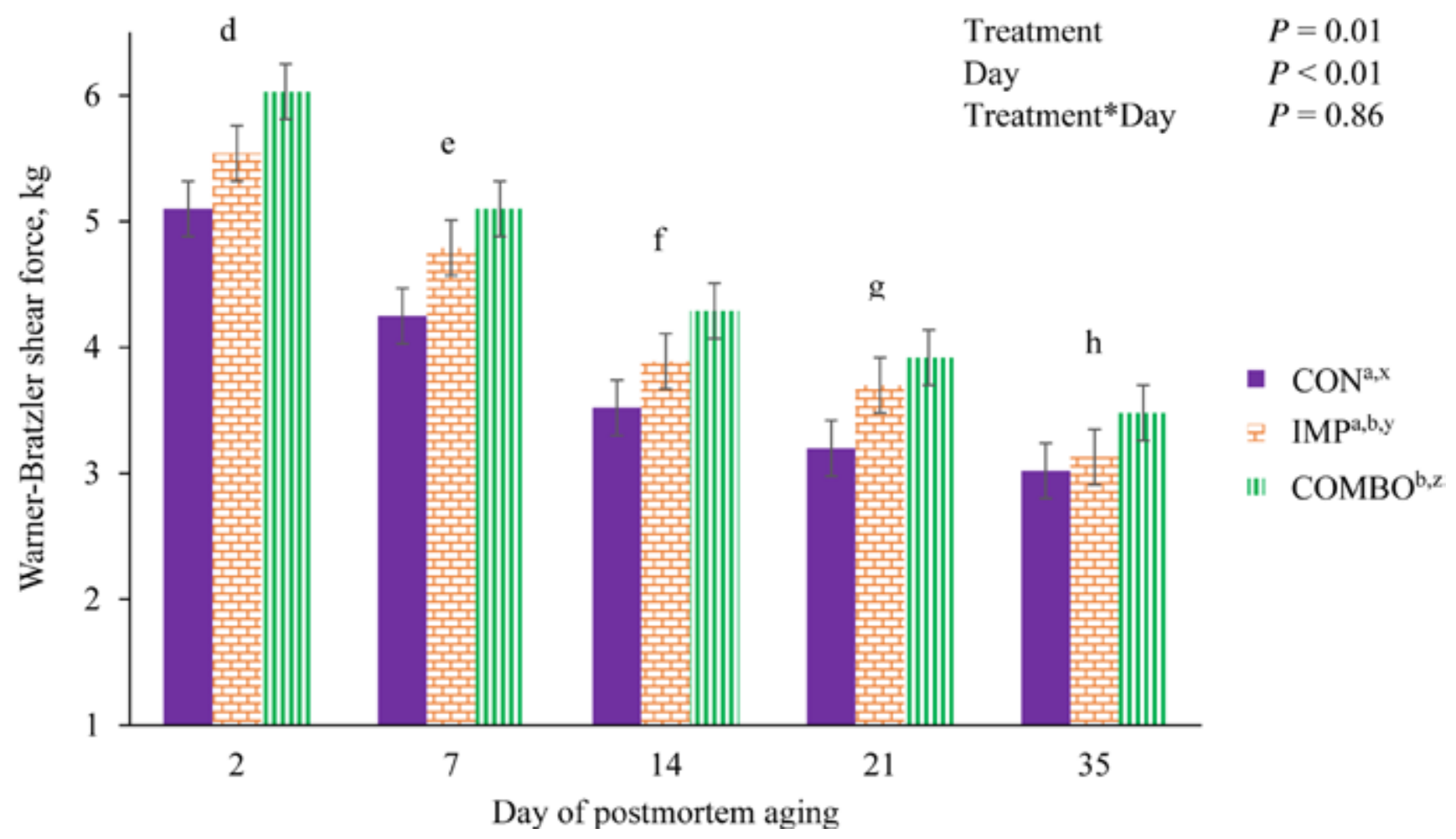

Figure 1. Days 2, 7, 14, 21, or 35 Longissimus lumborum steak Warner-Bratzler shear force values of crossbred heifers subjected to three growth-promoting programs. Crossbred heifers (group 1, $n=33$; group 2, $n=32$ ) were subjected to one of three treatments: no implant and no ractopamine hydrochloride (CON; Elanco Animal Health, Greenfield, IN); Component TE-200 implant (Elanco Animal Health) on d 0, no ractopamine hydrochloride (IMP); and Component TE-200 implant on $\mathrm{d} 0$ and ractopamine hydrochloride at $400 \mathrm{mg} \cdot \mathrm{d}^{-1} \cdot$ heifer $^{-1}$ for the last $28 \mathrm{~d}$ in group 1 and last $29 \mathrm{~d}$ in group 2 (COMBO). ${ }^{\text {a,b }}$ Treatments with a different superscript differ $(P<0.05){ }^{\text {d,e,f,g,h }}$ Days with a different superscript differ $(P<0.05)$. ${ }^{\mathrm{x}, \mathrm{y}, \mathrm{z}}$ Treatments with a different superscript tend to differ $(P<0.10)$.

loss was not affected by GP treatment or DOA $(P>$ $0.23)$. Treatment and DOA influenced WBSF values $(P<0.01)$. All DOA aging comparisons differed from one another indicating that as postmortem aging time was increased, shear force values of steaks decreased $(P<0.01)$. Over the entire aging study, COMBO steaks had greater $(P<0.01)$ shear force values when compared to the CON steaks, and tended to be different $(P=0.06)$ from IMP steaks. Sheer force of IMP steaks tended to be greater $(P<0.07)$ compared to CON steaks.

\section{Immunohistochemistry}

Growth-promoting treatment affected $(P=0.04)$ type I fiber percentage, tended to affect $(P=0.07)$ type IIX fiber type percentage, but had no effect $(P=0.48)$ on the percentage of type IIA fibers (Table 4). Muscle from IMP cattle had an increased $(P<0.01)$ percentage of type I fibers when compared to the CON cattle. Percentage of type I fibers for the COMBO muscle did not differ $(P=0.41)$ from IMP cattle, but tended to be greater $(P=0.08)$ compared to CON cattle. Muscle from the IMP treatment tended to have less $(P=0.07)$ type IIX fibers than CON muscle, while COMBO muscle possessed less $(P=0.03)$ type IIX fibers than CON muscle. There was no type IIX fiber percentage differences $(P=0.72)$ between IMP and COMBO muscles.

Growth promoting treatment tended to induce an increase in type I and IIX myofiber CSA $(P<0.10)$. Compared to CON type I fiber CSA, IMP fibers tended to be bigger $(P=0.07)$, while COMBO fibers were bigger $(P=0.05)$ than CON. The CSA of IMP and COMBO type I fibers were not different $(P=0.89)$ from each other. The CSA of type IIA fibers was impacted $(P<0.01)$ by GP treatment. The COMBO and IMP had increased type IIA CSA when compared to CON fibers $(P<0.01)$. When compared to each other, COMBO and IMP type IIA fiber CSA did not differ $(P$ $=0.76)$. Control muscle type IIX fiber CSA tended to be smaller $(P=0.07)$ than COMBO fibers and were also smaller $(P=0.05)$ than IMP muscle. Type IIX muscle fiber CSA did not differ $(P=0.89)$ between IMP and COMBO muscles.

\section{Collagen Solubility and Hydroxylysyl Pyridinoline Content}

There were no treatment $\times$ DOA interactions or treatment and DOA main effects for insoluble and total collagen content $(P>0.84$; Table 5). There were no treatment $\times$ DOA interaction or treatment main effect 
Table 4. Myosin heavy chain distribution and cross-sectional area of skeletal muscle fibers within the longissimus lumborum of crossbred heifers subjected to 3 growth-promoting programs

\begin{tabular}{|c|c|c|c|c|c|}
\hline \multirow[b]{2}{*}{ Item } & \multicolumn{3}{|c|}{ Treatment $^{1}$} & \multirow[b]{2}{*}{ SEM } & \multirow[b]{2}{*}{$P$-value } \\
\hline & $\mathrm{CON}$ & IMP & COMBO & & \\
\hline \multicolumn{6}{|l|}{ Myosin heavy chain type I } \\
\hline Percentage, $\%$ & $27.5^{\mathrm{a}, \mathrm{x}}$ & $31.0^{\mathrm{b}}$ & $29.9^{\mathrm{a}, \mathrm{b}, \mathrm{y}}$ & 1.0 & 0.04 \\
\hline Cross-sectional area, $\mu \mathrm{m}^{2}$ & $2083^{\mathrm{a}, \mathrm{x}}$ & $2279^{y}$ & $2293^{b, y}$ & 75 & 0.10 \\
\hline \multicolumn{6}{|l|}{ Myosin heavy chain type IIA } \\
\hline Percentage, $\%$ & 42.8 & 43.8 & 45.8 & 1.7 & 0.45 \\
\hline Cross-sectional area, $\mu \mathrm{m}^{2}$ & $3004^{\mathrm{a}}$ & $3541^{\mathrm{b}}$ & $3486^{\mathrm{b}}$ & 128 & $<0.01$ \\
\hline \multicolumn{6}{|l|}{ Myosin heavy chain type IIX } \\
\hline Percentage, $\%$ & $29.7^{\mathrm{a}, \mathrm{x}}$ & $25.2^{\mathrm{y}}$ & $24.3^{\mathrm{b}, \mathrm{y}}$ & 1.8 & 0.07 \\
\hline Cross-sectional area, $\mu \mathrm{m}^{2}$ & $3750^{\mathrm{a}, \mathrm{x}}$ & $4193^{b}$ & $4164^{b, y}$ & 161 & 0.10 \\
\hline
\end{tabular}

a,b Means within a row with a different superscript differ $(P<0.05)$.

$\mathrm{x}, \mathrm{y}$ Means within a row with a different superscript tend to differ $(P<0.10)$.

${ }^{1}$ Crossbred heifers (group 1, $n=33$; group 2, $n=32$ ) were subjected to 1 of 3 treatments: no implant and no ractopamine hydrochloride (CON; Elanco Animal Health, Greenfield, IN); Component TE-200 implant (Elanco Animal Health) on d 0, no ractopamine hydrochloride (IMP); and Component TE-200 implant on $\mathrm{d} 0$ and ractopamine hydrochloride at $400 \mathrm{mg}^{-1} \mathrm{~d}^{-1} \cdot \mathrm{heifer}^{-1}$ for the last $28 \mathrm{~d}$ in group 1 and last $29 \mathrm{~d}$ in group 2 (COMBO).

Table 5. Collagen characteristics after 2, 7, 14, 21, and $35 \mathrm{~d}$ of postmortem aging of longissimus lumborum steaks from crossbred heifers subjected to 3 exogenous growth-promoting programs

\begin{tabular}{|c|c|c|c|c|c|c|c|}
\hline \multirow[b]{2}{*}{ Item } & \multicolumn{3}{|c|}{ Treatment $^{1}$} & \multirow[b]{2}{*}{ SEM } & \multicolumn{3}{|c|}{$P$-value } \\
\hline & $\mathrm{CON}$ & IMP & COMBO & & $\mathrm{Trt}^{2}$ & $\mathrm{DOA}^{3}$ & Trt $\times$ DOA \\
\hline Soluble collagen ${ }^{4}$ & & & & 0.06 & 0.75 & 0.04 & 1.00 \\
\hline Day $2^{\mathrm{a}}$ & 1.00 & 0.98 & 0.94 & & & & \\
\hline Day $7^{\mathrm{a}, \mathrm{x}}$ & 0.99 & 0.94 & 0.93 & & & & \\
\hline Day $14^{\mathrm{a}, \mathrm{x}}$ & 0.98 & 0.95 & 0.95 & & & & \\
\hline Day $21^{\mathrm{a}, \mathrm{b}, \mathrm{y}}$ & 1.06 & 1.00 & 1.03 & & & & \\
\hline Day $35^{\mathrm{b}}$ & 1.09 & 1.06 & 1.05 & & & & \\
\hline Insoluble collagen ${ }^{4}$ & & & & 0.32 & 0.84 & 0.86 & 0.98 \\
\hline Day 2 & 7.28 & 7.19 & 7.16 & & & & \\
\hline Day 7 & 7.21 & 7.47 & 7.06 & & & & \\
\hline Day 14 & 7.17 & 7.25 & 7.00 & & & & \\
\hline Day 21 & 7.30 & 7.26 & 6.99 & & & & \\
\hline Day 35 & 7.08 & 7.15 & 7.05 & & & & \\
\hline Total collagen 4 & & & & 0.36 & 0.84 & 0.97 & 0.99 \\
\hline Day 2 & 8.29 & 8.18 & 8.10 & & & & \\
\hline Day 7 & 8.20 & 8.42 & 8.00 & & & & \\
\hline Day 14 & 8.15 & 8.20 & 7.95 & & & & \\
\hline Day 21 & 8.36 & 8.27 & 8.02 & & & & \\
\hline Day 35 & 8.17 & 8.21 & 8.10 & & & & \\
\hline Hydroxylysyl pyridinoline 5 & & & & 125 & 0.65 & 0.61 & 0.33 \\
\hline Day 2 & 1782 & 1441 & 1567 & & & & \\
\hline Day 7 & 1550 & 1664 & 1350 & & & & \\
\hline Day 14 & 1934 & 1385 & 1863 & & & & \\
\hline Day 21 & 1587 & 1635 & 1389 & & & & \\
\hline Day 35 & 1591 & 1505 & 1717 & & & & \\
\hline
\end{tabular}

a,b Days within soluble collagen with a different superscript differ $(P<0.05)$.

$\mathrm{x}, \mathrm{y}$ Days within soluble collagen with a different superscript tend to differ $(P<0.10)$.

${ }^{1}$ Crossbred heifers (group 1, $n=33$; group 2, $n=32$ ) were subjected to 1 of 3 treatments: no implant and no ractopamine hydrochloride (CON; Elanco Animal Health, Greenfield, IN); Component TE-200 implant (Elanco Animal Health) on d 0, no ractopamine hydrochloride (IMP); and Component TE-200 implant on $\mathrm{d} 0$ and ractopamine hydrochloride at $400 \mathrm{mg} \cdot \mathrm{d}^{-1} \cdot$ heifer $^{-1}$ for the last $28 \mathrm{~d}$ in group 1 and last $29 \mathrm{~d}$ in group 2 (COMBO).

${ }^{2} \mathrm{Trt}=$ Treatment.

${ }^{3} \mathrm{OA}=$ Day of aging.

${ }^{4}$ Expressed in mg collagen/g wet muscle.

${ }^{5}$ Expressed in ng hydroxylysyl pyridinoline/g wet muscle. 
Table 6. Pearson's correlation coefficients between Warner-Bratzler shear force and fiber cross-sectional area, soluble collagen, insoluble collagen, total collagen, and hydroxylysyl pyridinoline crosslink amount of longissimus lumborum steaks aged $2,7,14,21$, and $35 \mathrm{~d}_{\text {postmortem }}{ }^{1}$

\begin{tabular}{|c|c|c|c|c|c|}
\hline \multirow[b]{2}{*}{ Item } & \multicolumn{5}{|c|}{ Warner-Bratzler shear force, $\mathrm{kg}$} \\
\hline & Day 2 & Day 7 & Day 14 & Day 21 & Day 35 \\
\hline \multicolumn{6}{|l|}{ Cross-sectional area, $\mu \mathrm{m}^{2}$} \\
\hline Type I & $0.28 * *$ & 0.17 & $0.23 *$ & -0.04 & -0.11 \\
\hline Type IIA & $0.24 * *$ & 0.13 & 0.20 & 0.10 & -0.01 \\
\hline Type IIX & $0.21 *$ & 0.09 & 0.20 & 0.12 & -0.03 \\
\hline Soluble collagen, mg/g & 0.05 & $-0.24 *$ & $-0.23 *$ & 0.06 & -0.11 \\
\hline Insoluble collagen, mg/g & -0.01 & $-0.34 * *$ & $-0.33 * *$ & $-0.23 *$ & $-0.40 * * *$ \\
\hline Total collagen, mg/g & -0.05 & $-0.33 * *$ & $-0.33 * *$ & -0.19 & $-0.39 * * *$ \\
\hline Hydroxylysyl pyridinoline, $\mathrm{ng} / \mathrm{mg}$ & 0.07 & -0.04 & 0.03 & 0.01 & 0.12 \\
\hline \multicolumn{6}{|l|}{$* P<0.10$} \\
\hline \multicolumn{6}{|l|}{$* * P<0.05$} \\
\hline \multicolumn{6}{|l|}{$* * * P<0.01$} \\
\hline
\end{tabular}

for soluble collagen content $(P>0.75)$; however, there was a DOA effect $(P=0.04)$. Steaks aged for 2,7 , and 14-d had less soluble collagen than steaks aged $35 \mathrm{~d}$ $(P<0.03)$. Additionally, steaks aged for 7 and $14 \mathrm{~d}$ tended to have less soluble collagen than steaks aged $21 \mathrm{~d}(P<0.10)$. There was no treatment $\times$ DOA interaction or treatment and DOA effects for the amount of the HP crosslinks $(P>0.33)$.

\section{Correlation Coefficients}

Pearson's correlation coefficients between WBSF and fiber CSA and collagen characteristics are displayed in Table 6 . On d 2 of aging, the CSA of type I and IIA fiber types were positively correlated $(r=0.28$ and 0.24 , respectively) with WBSF $(P<0.05)$, while there was a tendency for type IIX fiber CSA to be correlated $(P=0.09 ; r=0.21)$. For the remaining aging periods, CSA of all fiber types were not correlated with WBSF $(P>0.11)$ except for a tendency for type I CSA to be positively correlated $(P=0.07 ; r=0.23)$ on $\mathrm{d}$ 14. No collagen characteristics were not correlated to WBSF at $\mathrm{d} 2$ of aging $(P>0.71)$. Soluble collagen was not correlated with WBSF on d 21, and $35(P>0.42)$, but tended to be negatively correlated $(P<0.08)$ with WBSF at $\mathrm{d} 7(r=-0.24)$ and $14(r=-0.23)$ of aging. Insoluble and total collagen contents were negatively correlated to WBSF on $\mathrm{d} 7(r=-0.34$ and -0.33 , respectively) and $14(P<0.05 ; r=-0.33)$, but not at 2 or 21 $\mathrm{d}(P>0.16)$. At $\mathrm{d} 35$ of aging, WBSF was negatively correlated to insoluble and total collagen content $(r=$ -0.40 and -0.39 , respectively; $P<0.01$ ). The amount of HP within the longissimus lumborum was not correlated to WBSF at any DOA $(P>0.59)$.

\section{DISCUSSION}

The use of GP in beef production can improve feedlot performance during the finishing phase and increase carcass yields (Lean et al., 2014; Wileman et al., 2009). In the current study, carcass characteristics associated with greater muscling were impacted by GP treatment. Hot carcass weight tended to be affected by the use of GP, as the COMBO and IMP carcasses were approximately $4 \%$ heavier than the CON carcasses. Ebarb et al. (2016) reported that carcasses from heifers implanted with the same implant tended to be $2 \%$ heavier than CON carcasses. Similarly, Boles et al. (2009) administered TBA/ $E_{2}$ implants to feedlot heifers and also reported increased $\mathrm{HCW}$ by $2 \%$ when compared to non-implanted heifers. Quinn et al. (2008) reported an increase in HCW by $2 \%$ for heifers that were not implanted, but received RH during the finishing period. Ebarb et al. (2016) observed 4\% heavier carcasses for heifers implanted and supplemented $\mathrm{ZH}$ during finishing when compared to the control heifers. In the current study, dressing percentage and yield grade were unaffected by GP treatment. In contrast, Ebarb et al. (2016) reported a tendency for dressing percentage to be increased due to GP treatment, while yield grade was decreased by $28 \%$ and $33 \%$ for carcasses from heifers implanted and heifers implanted and fed $\mathrm{ZH}$, respectively. Bruns et al. (2005) observed similar yield grade measures, but increased dressing percentage by $0.6 \%$ for carcasses from implanted steers fed $\mathrm{ZH}$ when compared to non-implanted steers. Herschler et al. (1995) reported no difference for yield grade and dressing percentage due to implant treatment. Talton et al. (2014) observed increased dressing percentage by $1.2 \%$ and no difference in yield grade for implanted heifers supplemented $\mathrm{RH}$ 
when compared to the non-RH supplemented implanted heifers. Therefore, carcass measures in the current study were typical of what is seen for implant only and implant/ RH supplemented carcasses.

As more nutrients are converted to lean muscle tissue, cattle supplemented with GP have a greater potential for increased lean muscle yields. This study demonstrated this mechanism with a 9 and $7.6 \%$ increase in LM area for COMBO and IMP loins, respectively, when compared to CON. Previously, Ebarb et al. (2016) observed a tendency for implanted heifers to have increased LM area by $11.9 \%$ when compared to the non-implanted controls. When the implanted heifers were fed $\mathrm{ZH}, \mathrm{LM}$ area increased $15.2 \%$ when compared to the controls. Cook et al. (2000) and Smith et al. (2007) observed an increase in LM area by as much as $18 \%$ after implanting heifers with a similar implant containing TBA and E2. With RH supplementation, Griffin et al. (2009) reported increased LM area. In contrast, Bryant et al. (2010) observed no difference in LM area for heifers subjected to RH. The current study also reported an increase for initial strip loin weight as the IMP and COMBO loins were $7 \%$ heavier than loins from CON heifers. Kellermeier et al. (2009) reported increased strip loin yield by $0.19 \%$ for steers subjected to combination implants during finishing. In contrast, Ebarb et al. (2016) reported no increase in strip loin weight when heifers were subjected to combination implants and $\mathrm{ZH}$. Garmyn and Miller (2014) reported increased strip loin weight by 3 and $7 \%$ for steers supplemented $\mathrm{RH}$ and $\mathrm{ZH}$ during the finishing period, respectively. The improvements in LM area and strip loin weight demonstrate a positive effect of GP on lean muscle yields.

The use of GP diverts nutrients toward lean muscle deposition rather than adipose tissue, which can have impacts on carcass adipose measurements (Duckett et al., 1999). In the current study, heifers did not display differences in 12th rib subcutaneous fat or marbling scores when subjected to combination implants. In contrast, the implanted heifers in the study by Ebarb et al. (2016) tended to have less 12 th rib s. c. fat by $25 \%$ and tended to have decreased marbling score. Other early studies have displayed decreased marbling scores up to $15 \%$ for cattle that received a combination implant (Cecava and Hancock, 1994; Garber et al., 1990; Herschler et al., 1995). In agreement with the current study, some authors have also reported no change to 12 th rib subcutaneous fat or marbling score for cattle that were subjected to anabolic implants (Cook et al., 2000; DeHaan et al., 1990). Similarly, Talton et al. (2014) and Quinn et al. (2008) observed no difference in 12th rib subcutaneous fat or marbling score after supplementing heifers with RH. In contrast, Ebarb et al. (2016) reported ZH and implants decreased the 12 th rib subcutaneous fat by $35 \%$, but marbling scores were not changed. In the current study $\mathrm{RH}$ was supplemented for $28 \mathrm{~d}$, which is only a portion of the supplementation time allowed for that product, and heifers only received one implant during growth. Subjecting cattle to multiple implants, a greater concentration of $\mathrm{RH}$, or a more potent BAA can increase the magnitude of impact on adipose tissue, as the animals have a greater potential for lean deposition (Arp et al., 2014; Platter et al., 2003). Platter et al. (2003) reported increased marbling scores for steers that received one implant during finishing when compared to steers that received multiple implants during finishing. Arp et al. (2014) reported decreased marbling scores for steers that received 300 $\mathrm{mg} \mathrm{RH}$ or $6.8 \mathrm{mg} / \mathrm{kg} \mathrm{ZH}$ when compared to the nonsupplemented controls, while the steers that received $200 \mathrm{mg}$ RH did not differ from the controls. Altogether, technologies that increase skeletal muscle deposition can negatively impact adipose measurements (Duckett et al., 1999; Maxwell et al., 2015).

The negative impact of GP on meat tenderness can be detrimental to consumers' acceptance of beef products. The effects of GP on tenderness are more prominent prior to postmortem aging. This was observed by Boler et al. (2012) when steaks from cattle fed RH and aged $4 \mathrm{~d}$ had $13 \%$ greater WBSF compared to controls; however, after 7,14 , and 21 DOA, WBSF values did not differ. Other literature indicate IMP steaks required approximately 7 DOA to be similar to CON steaks, while COMBO steaks required $21 \mathrm{DOA}$ to be similar to CON steaks (Quinn et al., 2008; Schneider et al., 2007). Ebarb et al. (2016) observed steaks from implanted heifers took $14 \mathrm{~d}$ to reach WBSF values similar to controls, but steaks from heifers implanted and fed ZH did not reach control steak WBSF values after $35 \mathrm{~d}$ of aging. The lack of an interaction between treatment and DOA in the current study indicates all steaks, regardless of treatment, aged in the same manner during postmortem aging. Across the entire aging study and compared to CON steaks, the current study observed a 7.3 and $19.6 \%$ increase in WBSF values for the IMP and COMBO steaks, respectively. These increases in WBSF were not due to either cook loss or muscle $\mathrm{pH}$, as there were no GP effects on these measures. Day of aging did increase $\mathrm{pH} 0.1$ unit, and it is hypothesized this was due to the change in location of the $\mathrm{pH}$ measurement. Smith et al. (2007) reported steers subjected to an implant containing $200 \mathrm{mg}$ TBA and $28 \mathrm{mg}$ E2 produced steaks with $15 \%$ greater WBSF when aged over a $21-d$ period. Other authors have reported no differences in WBSF for cattle that received an aggressive implant during growth (Barham et al., 2003; Schoonmaker et al., 2001). Gruber et al. (2008) reported increased WBSF for steers fed $\mathrm{RH}$, while Quinn et al. (2008) observed no difference in shear force values of steaks from heifers subjected to RH. Overall, utilization of these 2 GP protocols have a negative effect of heifer steak WBSF values. 
The literature would indicate that GP can affect muscle fiber type. Chung et al. (2012) observed no difference in the mRNA expression of myosin heavy chains within the LM of steers that were subjected to TBA and E2 implants when compared to non-implanted cattle. In pigs, RH commonly shifts muscle fiber isoform toward the more glycolytic IIB isoform (Aalhus et al., 1992; Depreux et al., 2002). Utilizing a different BAA, Vestergaard et al. (1994) reported cimaterol caused an increase in type IIB(X) fibers at the expense of type I and IIA fibers. In cull cows, Gonzalez et al. (2007) reported no difference in the percentage of type I and II fibers for cattle subjected to RH and TBA separately, yet when the 2 GP were combined the percentage of type II fibers was increased. Due to the authors' immunohistochemistry procedure, they were unable to detect shifts between the isoforms of type II fibers. In a follow-up study again with cull cows, Gonzalez et al. (2008) observed an increase in type II fiber percentage for RH supplemented cattle when compared to the control cattle, but no differences in type IIA or IIX mRNA expression were detected when measured by real-time PCR. Recently, Ebarb et al. (2016) reported increased percentage of type IIA fibers at the expense of type IIX fibers for heifers subjected to GP during finishing. The current study observed a 3\% average increase in type I fiber percentage, which occurred due to a $5 \%$ average decrease in type IIX fiber percentage when both GP protocols were used. The exact reason for inconsistent fiber type responses are unknown; however, Aalhus et al. (1992) concluded the response to GP is dependent on initial fiber type. Therefore, different ages, breeds, and sexes, in addition to different compounds utilized, could be the source of variable results.

Since the number of muscle fibers is fixed after birth, the growth of muscle tissue due to implants and BAA is caused by an increase in CSA of muscle fibers (Stickland, 1978). The influence of muscle fiber CSA on meat tenderness was illustrated in Ebarb et al. (2016) where all three fiber types were moderately correlated to WBSF through 14 DOA and type IIX fibers remained moderately correlated through 35 DOA. Chriki et al. (2012) reported an association between larger fiber CSA and reduced tenderness values for steaks aged to $14 \mathrm{~d}$. In the current study, all 3 fiber types were positively correlated to WBSF only at $\mathrm{d} 2$ of aging, but these correlations were eliminated by postmortem aging. Similar to the current study, Crouse et al. (1991) found muscle fiber CSA was correlated to WBSF only when considered early postmortem. Whipple et al. (1990) reported no muscle fiber CSA correlations to WBSF at 14 DOA and Vestergaard et al. (2000) found the same result when LM, semitendinosus, and supraspinatus were aged $8 \mathrm{~d}$. The rapid loss of association between muscle fiber CSA and WBSF in the current study could be due to the GP not stimulating as large of an increase in CSA as what was seen in Ebarb et al. (2016). Ebarb et al. (2016) reported the GP treatments increased type I, IIA, and IIX fiber CSA by a maximum of $12 \%, 21 \%$, and $28 \%$, respectively. Growth-promoting technologies in the current study only increased type I, IIA, and IIX fiber CSA by $10 \%, 17 \%$, and $11 \%$, respectively. Similar to the current study, Fritsche et al. (2000) reported increased fiber CSA for implanted steers when compared to non-implanted steers. Gonzalez et al. (2007) displayed an increase in type I CSA and no change to type II fiber CSA in the LM muscle of culled beef cows supplemented RH. In a subsequent study utilizing younger-growing cattle, Gonzalez et al. (2010) reported no difference in type I and II fiber CSA for feedlot steers fed a lower dose of RH. The major difference between the results of Ebarb et al. (2016) and the current study is the implant/BAA treatment increase in type IIX CSA. Ebarb et al. (2016) utilized $\mathrm{ZH}$ as the BAA, which caused an increase in type IIX CSA over the implant effect. These are the largest fibers in beef muscle and had the strongest correlation to WBSF. Since RH does not elicit as potent of a growth response as ZH (Avendaño-Reyes et al., 2006) and it did not increase type IIX fiber CSA over the implant fibers, this could be the reason for a lack of correlation on WBSF in the current study. Finally, the lack of a strong correlation between muscle fiber CSA and WBSF may indicate alterations in the calpain proteolytic system play a larger role in the establishment of tenderness in this study. Gerken et al. (1995) observed no implant effects on $\mu$ - and $\mathrm{m}$ - calpain activity or WBSF, but found a $16 \%$ increase in $24-\mathrm{h}$ calpastatin activity. Strydom et al. (2009) found RH increased 24-h calpastatin activity 48\%, but WBSF was not different than control. Therefore, because calpain proteolytic system enzymes have historically been measured at 24-h postmortem and not over extended aging, this system should be explored further.

As skeletal muscle deposition is increased, the network of collagen is continuously remodeled (Purslow, 2014). As a result, newly synthesized collagen is deposited in the muscle tissue to support the growing structure. Immature or recently synthesized collagen consists of divalent crosslinks which are heat soluble, while mature collagen consists of trivalent crosslink bonds that are associated with decreased heat solubility (Bailey and Light, 1989; McCormick, 2009). Growthpromoting treatment did not impact collagen measurements for this study including the heat-stable trivalent crosslink HP. Ebarb et al. (2016) also reported no GP effects for all of the collagen measures. Similar to the current study, Calkins et al. (1986) reported no change to total or soluble collagen with the use of zeranol implants. Strydom et al. (2009) observed no difference for amounts of total collagen and the solubility of collagen for RH and control treatments. Similarly, Martin et al. 
(2014) reported similar total collagen percentage between non-RH fed and RH fed steers. In contrast, Roy et al. (2015) reported the amount of HP increased within the gluteus medius and semitendinosus when steers were implanted, but there was no difference in HP when RH was supplemented. Therefore, GP utilization seems to elicit no effect on collagen crosslinking and solubility.

Ebarb et al. (2016) demonstrates the ability of postmortem aging to reduce the influence of muscle fiber CSA on tenderness and the emerging influence of the collagen network. Marbling's correlation to WBSF also decreases throughout aging to where there is no correlation by d 14 postmortem (Lonergan et al., 2001). In agreement with Ebarb et al. (2016), extended postmortem aging increased the amount of soluble collagen present in raw muscle by $10 \%$ from d 2 to 35 of aging. Jeremiah and Martin (1981) also reported increased collagen solubility by $12 \%$ for LD samples aged from $24 \mathrm{~h}$ to $20 \mathrm{~d}$. In contrast to what one would expect, negative correlations were seen for insoluble and total collagen content from d 7 through 35 of aging. Ebarb et al. (2016) found positive insoluble and total collagen content correlations with WBSF became significant at d 21 and 35 of aging, which agrees with several studies that relate decreased connective tissue amount to improved tenderness during postmortem aging (Jeremiah and Martin, 1981; Lepetit, 2007; Renand et al., 2001; Rhee et al., 2004). It is unclear why in the current study negative correlations were found, but it is hypothesized randomizing the loin to have equal DOA assigned to the different locations throughout the loin and freezing the samples before WBSF and collagen analyses, which were both not done by Ebarb et al. (2016), may have created the unexpected result. These are experimental conditions that must be explored further and considered when designing future studies.

\section{LITERATURE CITED}

Aalhus, J. L., A. L. Schaefer, A. C. Murray, and D. M. Jones. 1992. The effect of ractopamine on myofiber distribution and morphology and their relation to meat quality in swine. Meat Sci. 31:397-409. doi:10.1016/0309-1740(92)90023-W

American Meat Science Association (AMSA). 1995. Research guidelines for cookery, sensory evaluation and instrumental tenderness measurements of fresh meat. Natl. Livest. Meat Board, Chicago, IL.

Association of Official Analytical Chemists. 2005. Official methods of analysis. 18th ed. Assoc. Off. Anal. Chem., Gaithersburg, MD.

Arp, T. S., S. T. Howard, D. R. Woerner, J. A. Scanga, D. R. McKenna, W. H. Kolath, P. L. Chapman, J. D. Tatum, and K. E. Belk. 2014. Effects of dietary ractopamine hydrochloride and zilpaterol hydrochloride supplementation on performance, carcass traits, and carcass cutability in beef steers. J. Anim. Sci. 92:836-843. doi:10.2527/jas.2013-7122
Avendaño-Reyes, L., T. Torres-Rodríguez, F. J. Meraz-Murillo, C. Pérez-Linars, F. Figueroa-Saavedra, and P. H. Robinson. 2006. Effects of two $\beta$-adrenergic agonists on finishing performance, carcass characteristics, and meat quality of feedlot steers. J. Anim. Sci. 84:3259-3265. doi:10.2527/jas.2006-173

Bailey, A. J., and N. D. Light. 1989. Connective tissue in meat and meat products. Elsevier Applied Science, London.

Barham, B. L., J. C. Brooks, J. R. Blanton, Jr., A. D. Herring, M. A. Carr, C. R. Kerth, and M. F. Miller. 2003. Effects of growth implants on consumer perceptions of meat tenderness in beef steers. J. Anim. Sci. 81:3052-3056. doi:10.2527/2003.81123052x

Bergman. I., and R. Loxley. 1963. Two improved and simplified methods for spectrophotometric determination of hydroxyproline. Anal. Chem. 35:1961-1965.doi:10.1021/ac60205a053

Boler, D. D., A. L. Shreck, D. B. Faulkner, J. Killefer, F. K. McKeith, J. W. Homm, and J. A. Scanga. 2012. Effect of ractopamine hydrochloride (Optaflexx) dose on live performance, carcass characteristics and tenderness in early weaned beef steers. Meat Sci. 92:458-463. doi:10.1016/j.meatsci.2012.05.011

Boles, J. A., D. L. Boss, K. I. Neary, K. C. Davis, and M. W. Tess. 2009. Growth implants reduced tenderness of steaks from steers and heifers with different genetic potentials for growth and marbling. J. Anim. Sci. 87:269-274. doi:10.2527/jas.2008-1256

Bruns, K. W., R. H. Pritchard, and D. L. Boggs. 2005. The effect of stage of growth and implant exposure on performance and carcass composition in steers. J. Anim. Sci. 83:108-116. doi: $10.2527 / 2005.831108 \mathrm{x}$

Bryant, T. C., T. E. Engle, M. L. Galyean, J. J. Wagner, J. D. Tatum, R. V. Anthony, and S. B. Laudert. 2010. Effects of ractopamine and trenbolone acetate implants with or without estradiol on growth performance carcass characteristics, adipogenic enzyme activity, and blood metabolites in feedlot steers and heifers. J. Anim. Sci. 88:4102-4119. doi:10.2527/jas.2010-2901

Calkins, C. R., D. C. Clanton, T. J. Berg, and J. E. Kinder. 1986. Growth, carcass, and palatability traits of intact males and steers implanted with zeranol or estradiol early and throughout life. J. Anim. Sci. 62:625-631. doi:10.2527/jas1986.623625x

Cecava, M. J., and D. L. Hancock. 1994. Effects of anabolic steroids on nitrogen metabolism and growth of steers fed corn silage and corn-based diets supplemented with urea or combinations of soybean meal and feathermeal. J. Anim. Sci. 72:515-522. doi: $10.2527 / 1994.722515 \mathrm{x}$

Chriki, S., G. E. Gardner, C. Jurie, B. Picard, D. Micol, J. P. Brun, L. Journaux, and J. F. Hocquette. 2012. Cluster analysis application identifies muscle characteristics of importance for beef tenderness. BMC Biochem. 13:29 p.29-40. doi:10.1186/1471-2091-13-29

Chung, K. Y., T. J. Baxa, S. L. Parr, L. D. Lunqué, and B. J. Johnson. 2012. Administration of estradiol, trenbolone acetate, and trenbolone acetate/estradiol implants alters adipogenic and myogenic gene expression in bovine skeletal muscle. J. Anim. Sci. 90:14211427. doi: $10.2527 /$ jas.2010-3496

Cook, R. B., J. D. Popp, T. A. McAllister, J. P. Kastelic, and R. Harland. 2000. Effects of immunization against GnRH, melengestrol acetate, and a trenbolone acetate/estradiol implant on growth and carcass characteristics of beef heifers. Theriogenology 55:973-981. doi:10.1016/S0093-691X(01)00458-7

Cross, H. R., Z. L. Carpenter, and G. C. Smith. 1973. Effects of intramuscular collagen and elastin on bovine muscle tenderness. J. Food Sci. 38:998-1003. doi:10.1111/j.1365-2621.1973.tb02133.x

Crouse, J. D., M. Koohmaraie, and S. D. Seideman. 1991. The relationship of muscle fibre size to tenderness of beef. Meat Sci. 30:295302. doi:10.1016/0309-1740(91)90039-S 
DeHaan, K. C., L. L. Berger, D. J. Kesler, F. K. McKeith, D. B. Faulkner, G. F. Cmarik, and R. J. Favero. 1990. Effects of prenatal testosterone treatment and postnatal steroid implantation on growth performance and carcass traits of heifers and steers. J. Anim. Sci. 68:2198-2207. doi:10.2527/1990.6882198x

Depreux, F. F. S., A. L. Grant, D. B. Anderson, and D. E. Gerrard. 2002. Paylean alters myosin heavy chain isoform content in pig muscle. J. Anim. Sci. 80:1888-1894. doi:10.2527/2002.8071888x

Duckett, S. K., D. G. Wagner, F. N. Owens, H. G. Dolezal, and D. R Gill. 1999. Effect of anabolic implants on beef intramuscular lipid content. J. Anim. Sci. 77:1100-1104. doi:10.2527/1999.7751100x

Duckett, S. K., and S. L. Pratt. 2014. Meat Science and Muscle Biology Symposium: Anabolic implants and meat quality. J. Anim. Sci. 92:3-9. doi:10.2527/jas.2013-7088

Ebarb, S. M., J. S. Drouillard, K. R. Maddock-Carlin, K. J. Phelps, M. A. Vaughn, D. D. Burnett, C. L. Van Bibber-Krueger, C. B Paulk, D. M. Grieger, and J. M. Gonzalez. 2016. Effect of growthpromoting technologies on Longissimus lumborum muscle fiber morphometrics, collagen solubility, and cooked meat tenderness. J. Anim. Sci. 94:869-881. doi:10.2527/jas.2015-9888

Fritsche, S., M. D. Solomon, E. W. Paroczay, and T. S. Rumsey. 2000. Effects of growth-promoting implants on morphology of Longissimus and Semitendinosus muscles in finishing steers. Meat Sci. 56:229-237. doi:10.1016/S0309-1740(00)00047-4

Garber, M. J., R. A. Roeder, J. J. Combs, L. Eldridge, J. C. Miller, D. D. Hinman, and J. J. Ney. 1990. Efficacy of vaginal spaying and anabolic implants on growth and carcass characteristics in beef heifers. J. Anim. Sci. 68:1469-1475. doi:10.2527/1990.6851469x

Garmyn, A. J., and M. F. Miller. 2014. MEAT SCIENCE AND MUSCLE BIOLOGY SYMPOSIUM - Implant and beta agonist impacts on beef palatability. J. Anim. Sci. 92:10-20. doi:10.2527/ jas.2013-7097

Gerken, C. L., J. D. Tatum, J. B. Morgan, and G. C. Smith. 1995. Use of genetically identical (clone) steers to determine the effects of estrogenic and androgenic implants on beef quality and palatability characteristics. J. Anim. Sci. 73:3317-3324. doi: $10.2527 / 1995.73113317 x$

Gonzalez, J. M., J. N. Carter, D. D. Johnson, S. E. Ouellette, and S. E. Johnson. 2007. Effect of ractopamine-hydrochloride and trenbolone acetate on Longissimus muscle fiber area, diameter, and satellite cell numbers in cull beef cows. J. Anim. Sci. 85:1893-1901. doi:10.2527/jas.2006-624

Gonzalez, J. M., R. D. Dijkhuis, D. D. Johnson, J. N. Carter, and S. E. Johnson. 2008. Differential response of cull cow muscles to the hypertrophic actions of ractopamine-hydrogen chloride. J. Anim. Sci. 86:3568-3574. doi:10.2527/jas.2008-1049

Gonzalez, J. M., S. E. Johnson, A. M. Stelzleni, T. A. Thrift, J. D. Savell, T. M. Warnock, and D. D. Johnson. 2010. Effect of ractopamine-HCl supplementation for 28 days on carcass characteristics, muscle fiber morphometrics, and whole muscle yields of six distinct muscles of the loin and round. Meat Sci. 85:379-384. doi:10.1016/j.meatsci.2010.02.004

Griffin, W. A., G. E. Erickson, B.D. Dicke, T.J. Klopfenstein, R.J. Cooper, D.J. Jordon, R.S. Swingle, W.M. Moseley, G.E. Sides, and D.J. Weigel. 2009. Effects of Ractopamine (Optaflexx) fed in combination with melengestrol acetate on feedlot heifer performance. Prof. Anim. Sci. 25:33-40.

Gruber, S. L., J. D. Tatum, T. E. Engle, K. J. Prusa, S. B. Laudert, A. L. Schroeder, and W. J. Platter. 2008. Effects of ractopamine supplementation and postmortem aging on Longissimus muscle palatability of beef steers differing in biological type. J. Anim. Sci 86:205-210. doi:10.2527/jas.2007-0201
Herschler, R. C., A. W. Olmsted, A. J. Edwards, R. L. Hale, T. Montgomery, R. L. Preston, S. J. Bartle, and J. J. Sheldon. 1995. Production responses to various doses and ratios of estradiol benzoate and trenbolone acetate implants in steers and heifers. J. Anim. Sci. 73:2873-2881. doi:10.2527/1995.73102873x

Hill, F. 1966. The solubility of intramuscular collagen in meat animals of various ages. J. Food Sci. 31:161-166. doi:10.1111/j.1365-2621.1966.tb00472.x

Jeremiah, L. E., and A. H. Martin. 1981. Intramuscular collagen content and solubility: Their relationship to tenderness and alteration by postmortem aging. Can. J. Anim. Sci. 61:53-61. doi:10.4141/cjas81-008

Kellermeier, J. D., A. W. Titlor, J. C. Brooks, M. L. Galyean, D. A. Yates, J. P. Hutcheson, W. T. Nichols, M. N. Streeter, B. J. Johnson, and M. F. Miller. 2009. Effects of zilpaterol hydrochloride with or without an estrogen-trenbolone acetate terminal implant on carcass traits, retail cutout, tenderness, and muscle fiber diameter in finishing steers. J. Anim. Sci. 87:3702-3711. doi:10.2527/jas.2009-1823

Lean, I. J., J. M. Thompson, and F. R. Dunshea. 2014. A meta-analysis of zilpaterol and ractopamine effects on feedlot performance, carcass traits, and shear strength of meat in cattle. PloS ONE. doi:10.1371/journal.pone.0115904

Lepetit, J. 2007. A theoretical approach of the relationships between collagen content, collagen cross-links and meat tenderness. Meat Sci. 76:147-159. doi:10.1016/j.meatsci.2006.10.027

Lonergan, S. M., E. Huff-Lonergan, B. R. Wiegand, and L. A. KrieseAnderson. 2001. Postmortem proteolysis and tenderization of top loin steaks from Brangus cattle. J. Muscle Foods 12:121-136. doi:10.1111/j.1745-4573.2001.tb00304.x

Lusk, J. L., J. A. Fox, T. C. Schroeder, J. Mintert, and M. Koohmaraie. 2001. Will consumers pay for guaranteed tender steak? Am. J. Agric. Econ. 83:529-550.

Martin, J. N., A. J. Garmyn, M. F. Miller, J. M. Hodgen, K. D. Pfeiffer, C. L. Thomas, R. J. Rathmann, D. A. Yates, J. P. Hutcheson, and J. C. Brooks. 2014. Comparative effects of beta-adrenergic agonist supplementation on the yield and quality attributes of selected subprimals from calf-fed Holstein steers. J. Anim. Sci. 92:4204 4216. doi:10.2527/jas.2014-7881

Maxwell, C. L., B. C. Bernhard, C. F. O’Neill, B. K. Wilson, C. G. Hixon, C. L. Haviland, A. N. Grimes, M. S. Calvo-Lorenzo, D. L. VanOverbeke, G. G. Mafi, C. J. Richards, D. L. Step, B. P. Holland, and C. R. Krehbiel. 2015. The effects of technology use in feedlot production systems on feedlot performance and carcass characteristics. J. Anim. Sci. 93:1340-1349. doi:10.2527/jas.2014-8127

McCormick, R. J. 2009. Collagen. In: M. Du and R. J. McCormick, editors, Applied Muscle Biology and Meat Science. CRC Press, New York. p. 129-148.

Moreno-Sánchez, N., C. Diaz, M. J. Carabano, J. Rueda, and J. L. Rivero. 2008. A comprehensive characterization of the fibre composition and properties of a limb (Flexor digitorum superficialis, membri thoracic) and a trunk (Psoas major) muscle in cattle. BMC Cell Biol. 9:67. doi:10.1186/1471-2121-9-67

North American Meat Processors. 2010. The meat buyer's guide. 6th ed. North American Meat Processors Association, Reston, VA.

Phelps, K. J., J. S. Drouillard, J. S. Jennings, B. E. Depenbusch, C. L. Van Bibber-Krueger, K. A. Miller, M. A. Vaughn, D. D. Burnett, S. M. Ebarb, T. A. Houser, S. E. Johnson, and J. M. Gonzalez. 2014. Effects of the Programmed Nutrition Beef Program on meat quality characteristics. J. Anim. Sci. 92:1780-1791. doi:10.2527/jas.2013-7231 
Platter, W. J., J. D. Tatum, K. E. Belk, J. A. Scanga, and G. C. Smith. 2003. Effects of repetitive use of hormonal implants on beef carcass quality, tenderness, and consumer ratings of beef palatability. J. Anim. Sci. 81:984-996. doi:10.2527/2003.814984x

Purslow, P. P. 2014. New developments on the role of intramuscular connective tissue in meat toughness. Annu. Rev. Food Sci. Technol. 5:133-153. doi:10.1146/annurev-food-030212-182628

Quinn, M. J., C. D. Reinhardt, E. R. Loe, B. E. Depenbusch, M. E. Corrigan, M. L. May, and J. S. Drouillard. 2008. The effects of ractopamine-hydrogen chloride (Optaflexx) on performance, carcass characteristics, and meat quality of finishing feedlot heifers. J. Anim. Sci. 86:902-908. doi:10.2527/jas.2007-0117

Renand, G., B. Picard, C. Touraille, P. Berge, and J. Lepetit. 2001. Relationships between muscle characteristics and meat quality traits of young Charolais bulls. Meat Sci. 59:49-60. doi:10.1016/ S0309-1740(01)00051-1

Rhee, R. J., T. L. Wheeler, S. D. Shackelford, and M. Koohmaraie. 2004. Variation in palatability and biochemical traits within and among eleven beef muscles. J. Anim. Sci. 82: 534-550. doi: $10.2527 / 2004.822534 \mathrm{x}$

Roy, B. C., G. Sedgewick, J. L. Aalhus, J. A. Basarab, and H. L. Bruce. 2015. Modification of mature non-reducible collagen cross-link concentrations in bovine $\mathrm{m}$. gluteus medius and semitendinosus with steer age at slaughter, breed cross and growth promotants. Meat Sci. 110:109-117. doi:10.1016/j.meatsci.2015.07.008

Schiaffino, S., L. Gorza, S. Sartore, L. Saggin, S. Ausoni, M. Vianello, K. Gundersen, and T. Lomo. 1989. Three myosin heavy chain isoforms in type 2 skeletal muscle fibres. J. Muscle Res. Cell Motil. 10:197-205. doi:10.1007/BF01739810

Schneider, B. A., J. D. Tatum, T. E. Engle, and T. C. Bryant. 2007. Effects of heifer finishing impants on beef carcass traits and Longissimus tenderness. J. Anim. Sci. 85:2019-2030. doi:10.2527/jas.2007-0004

Schoonmaker, J. P., F. L. Fluharty, S. C. Loerch, T. B. Turner, S. J. Moeller, and D. M. Wulf. 2001. Effect of weaning status and implant regimen on growth, performance, and carcass characteristics of steers. J.Anim. Sci. 79:1074-1084. doi:10.2527/2001.7951074x
Smith, S. H., and M. D. Judge. 1991. Relationship between pyridinoline concentration and thermal stability of bovine intramuscular collagen. J. Anim. Sci. 69:1989-1993. doi:10.2527/1991.6951989x

Smith, K. R., S. K. Duckett, M. J. Azain, R. N. Sonon, Jr., and T. D. Pringle. 2007. The effect of anabolic implants on intramuscular lipid deposition in finished beef cattle. J. Anim. Sci. 85:430-440. doi:10.2527/jas.2006-280

Stickland, N. C. 1978. A quantitative study of muscle development in the bovine foetus (Bos indicus). Anat. Histol. Embryol. 7:193205. doi:10.1111/j.1439-0264.1978.tb00795.x

Strydom, P. E., L. Frylinck, J. L. Montgomery, and M. F. Smith. 2009. The comparison of three $\beta$-agonists for growth performance, carcass characteristics and meat quality of feedlot cattle. Meat Sci. 81:557-564. doi:10.1016/j.meatsci.2008.10.011

Talton, C. S., A. M. Stelzleni, J. S. Shook, G. M. Hill, C. R. Kerth, M. Pence, and T. D. Pringle. 2014. Effects of ovariectomization and ractopamine hydrochloride inclusion on heifer feedlot performance, meat yield, and tenderness of select muscles. Meat Sci. 96:73-81. doi:10.1016/j.meatsci.2013.06.016

Vestergaard, M., P. Henckel, N. Oksbjerg, and K. Sejrsen. 1994. The effect of cimaterol on muscle fiber characteristics, capillary supply, and metabolic potentials of longissimus and semitendinosus muscles from young Friesian bulls. J. Anim. Sci. 72:2298-2306. doi:10.2527/1994.7292298x

Vestergaard, M., P. Henckel, N. Oksbjerg, and K. Sejrsen. 2000. Influence of feeding intensity, grazing and finishing feeding on meat and eating quality of young bulls and the relationship between muscle fibre characteristics, fibre fragmentation and meat tenderness. Meat Sci. 54:187-195. doi:10.1016/ S0309-1740(99)00098-4

Whipple, G., M. Koohmaraie, M. E. Dikeman, and J. D. Crouse. 1990. Predicting beef-longissimus tenderness from various biochemical and histological muscle traits. J. Anim. Sci. 68:4193-4199. doi:10.2527/1990.68124193x

Wileman, B. W., D. U. Thomson, C. D. Reinhardt, and D. G. Renter. 2009. Analysis of modern technologies commonly used in beef cattle production: Conventional beef production versus nonconventional production using meta-analysis. J. Anim. Sci. 87:3418-3426. doi:10.2527/jas.2009-1778 